\title{
Pandemic Risk Management for Public Health Care Schemes
}

\author{
Zhengqiao Liu ${ }^{1}$, Yang-Che $W^{2 *}{ }^{2 *}$ Mei-Chih Wang ${ }^{3}$, Yue Ding ${ }^{4}$ and Tien-Trung Nguyen ${ }^{5}$ \\ ${ }^{1}$ Business School of Yango University, Fuzhou, China, ${ }^{2}$ Department of Finance, College of Finance, Feng Chia University, \\ Taichung, Taiwan, ${ }^{3}$ Center for Chinese Social and Management Studies, Tunghai University, Taichung, Taiwan, ${ }^{4}$ College of \\ Finance and Statistics, Hunan University, Changsha, China, ${ }^{5}$ Faculty of Finance and Accounting, Nguyen Tat Thanh \\ University, Ho Chi Minh City, Vietnam
}

OPEN ACCESS

Edited by:

Chi Wei Su,

Qingdao University, China

Reviewed by:

Hung Fung,

University of Missouri-St. Louis,

United States

Guvenc Kockaya,

ECONix Research, Analysis and

Consultancy Plc., Turkey

*Correspondence:

Yang-Che Wu

wuyangche@fcu.edu.tw

Specialty section:

This article was submitted to

Health Economics,

a section of the journal

Frontiers in Public Health

Received: 25 April 2021

Accepted: 23 June 2021

Published: 27 July 2021

Citation:

Liu Z, Wu Y-C, Wang M-C, Ding Y and Nguyen T-T (2021) Pandemic Risk

Management for Public Health Care

Schemes.

Front. Public Health 9:700021. doi: 10.3389/fpubh.2021.700021
The coronavirus disease 2019 (COVID-19) caused by a novel coronavirus, severe acute respiratory syndrome coronavirus 2 , has caused a large death, a range of serious health problems, and significant economic costs in many countries around the world. This study analyzes statistical characteristics of pandemic disasters using historical records since the Middle Ages. Compared to literature which studies the effect of the COVID- 19 pandemic on the financial market, this paper attempts to find two financial instruments in the financial market to hedge pandemic risks. Two instruments could be useful for public health care schemes to increase their assets or decrease their liabilities during the pandemic period, namely, assets in the form of a biotechnology investment portfolio and liabilities in the form of pandemic bonds. Empirical results show the feasibility of such instruments and the informational efficiency of the U.S. stock market.

Keywords: pandemic risk management, COVID-19, pandemic probability model, public health care scheme, pandemic hedging

\section{INTRODUCTION}

Epidemics and pandemics have afflicted humanity throughout recorded history, as shown in Table 1. An epidemic is defined as the rapid spread of disease in a large group of individuals beyond the normal level of infection that would be expected in a given population and region over a short period of time. A pandemic refers to an epidemic that has spread over several countries or continents. Compared with sudden catastrophic events (earthquakes, floods, hurricanes, and volcanic eruptions), epidemics and pandemics occur over a relatively long period, as there can be many months or even years between the beginning and the end of these health disasters. For example, to date, the current coronavirus disease 2019 (COVID-19) outbreak has lasted over a year. Therefore, there would be enough time to make use of financial instruments to hedge pandemic risk.

The effects of historical epidemics and pandemics on the financial market vary depending on location and era. Figure 1 presents the slip chart of the Dow Jones Industrial Average (DJIA) index and the historical pandemic records. Not all pandemics make the stock market go down a lot. The epidemics in the eighteenth and nineteenth centuries had limited financial effects because most epidemics were local ones that lasted a few months but not pandemics that affected the global world. In addition, different cities had their own stock exchanges, cross-market arbitrages stoped stock crashes in the infected cities. However, as human activities tend to globalization, worldwide pandemics show a different reality and then cause investor panic. Compared to the COVID-19 effects on the market with the Spanish Flu in 1918, the DJIA index stayed relatively stable, not 
dropping more than 5\% during the period from 1918 to 1920. After it was over, the U.S. economy grew by $42 \%$ between 1921 and the stock market crash in 1929. The flu killed about 40 million people or $2 \%$ of the global population. About 550,000 Americans died of the flu, half a percent of the U.S. population. European and US stock markets reacted significantly, and negatively, to the surging death rates during the Spanish Flu (1). Since World War I was over at the end of 1918, so the overlap period makes it difficult to discriminate between the economic and financial effects of the war and those of pandemic. However, COVID-19 had a different effect on the U.S. stock market. The DJIA index was down 37\% (on March 13) from an all-time high in February. At a similar time period, the S\&P 500 and the techheavy Nasdaq dropped over 31 and 40\%, respectively. The U.S. economy recovers gradually as job positions increasing and the service sectors reopening. Compared to literature focusing on the effect of the COVID-19 pandemic on the financial market (14 ), this paper attempts to find financial instruments in financial market for the public health care schemes (PHCS) to hedge pandemic risks.

There exist some catastrophe derivatives traded in financial market for hedging natural disasters such as catastrophe loss indexes, catastrophe bonds, and catastrophe equity puts or contingent surplus notes. A lot of literature study the effectiveness and efficience of catastrophe risk management via these derivative (5-7). Few financial derivatives are based on pandemics or epidemics. Less literature focus on how to employ financial instruments to manage pandemic risk. The World Bank issued two pandemic bonds with a total face value of US\$320 million in 2017. These bonds were designed to offer funds to lowincome countries to cover costs associated with the outbreak of any one of six diseases. Gründl and Regele (8) proposed a concept of pandemic partnership bonds, which governments could issue to insure themselves against future pandemic-related risks, with private and institutional investors providing the funding. This study shows that pandemic bonds may reduce the revenue volatility of public health care schemes.

The demand for medical treatments and vaccinations increases quickly as an epidemic becomes a pandemic. This tends to support the stock prices of firms engaged in medicine and biotechnology. If the relationship between newly diagnosed epidemics/pandemics and biotechnology stocks is strongly positive, insurers could build and adjust an investment portfolio of these stocks as a pandemic spread. The profit from the portfolio would offset some of the cost of pandemic-related claims. This study shows that these stocks are highly correlated to the spread of the COVID-19 pandemic.

This study makes three major contributions to the literature. First, we survey the statistical characteristics of pandemic historical records. The result shows that building a sound epidemic prevention system has become more necessary and important over time. Second, we show the feasibility of innovative financial instruments that could be employed effectively to cover a substantial amount of the cost of medical

TABLE 1 | Pandemics since the middle ages.

\begin{tabular}{|c|c|c|c|}
\hline Years & Diseases & Reported region & Deaths \\
\hline $1347-1351$ & Bubonic Plague & Europe & Over 50 million \\
\hline 1489 & Typhus & Europe & 17,000 \\
\hline 1500s & Smallpox & Europe, Americas & 12-25 million in Mexico \\
\hline 1510 & Influenza & Global & Unknown \\
\hline $1557-1558$ & Influenza & Europe & Unknown, 8,000 in London \\
\hline 1580 & Influenza & Asia, Africa, Europe, America & Unknown, 8,000 deaths in Rome \\
\hline 1635,1656 & Measles & Britain, Europe & Unknown \\
\hline $1700 s$ & Yellow Fever & Americas, Europe, Africa & 10,000 deaths in Philadelphia \\
\hline 1729-1730, 1732-1733, & Influenza & Global & 0.5 million \\
\hline $1761-1762$ & Influenza & Americas, Europe & Unknown \\
\hline $1780-1782$ & Influenza & China, India, Europe, America & Unknown \\
\hline $1788-1790$ & Influenza & Europe, North America & 0.8 million \\
\hline $1800 s$ & Cholera & Europe, Americas, Asia & 50-100 million \\
\hline 1830-1831, 1832-1833 & Influenza & China, Russia, Europe & 0.9 million \\
\hline 1889-1893 & Influenza/Russian Flu & Global & 1 million \\
\hline 1918-1919 & Influenza/Spanish Flu & Global & 40-50 million \\
\hline 1957-1958 & Influenza/Asian Flu & Global & 1-1.5 million \\
\hline 1968 & Influenza/Hong Kong & Global & 0.75-1 million \\
\hline 1979 & HIV/AIDS & Global & 35 million \\
\hline 1977-1978 & Influenza/Russian Flu & Global & Unknown \\
\hline 2009-2010 & Influenza/Swine Flu & Global & 284,500 \\
\hline 2003 & SARS & Global & 774 \\
\hline 2019 & COVID-19 & Global & 2.9 million \\
\hline
\end{tabular}




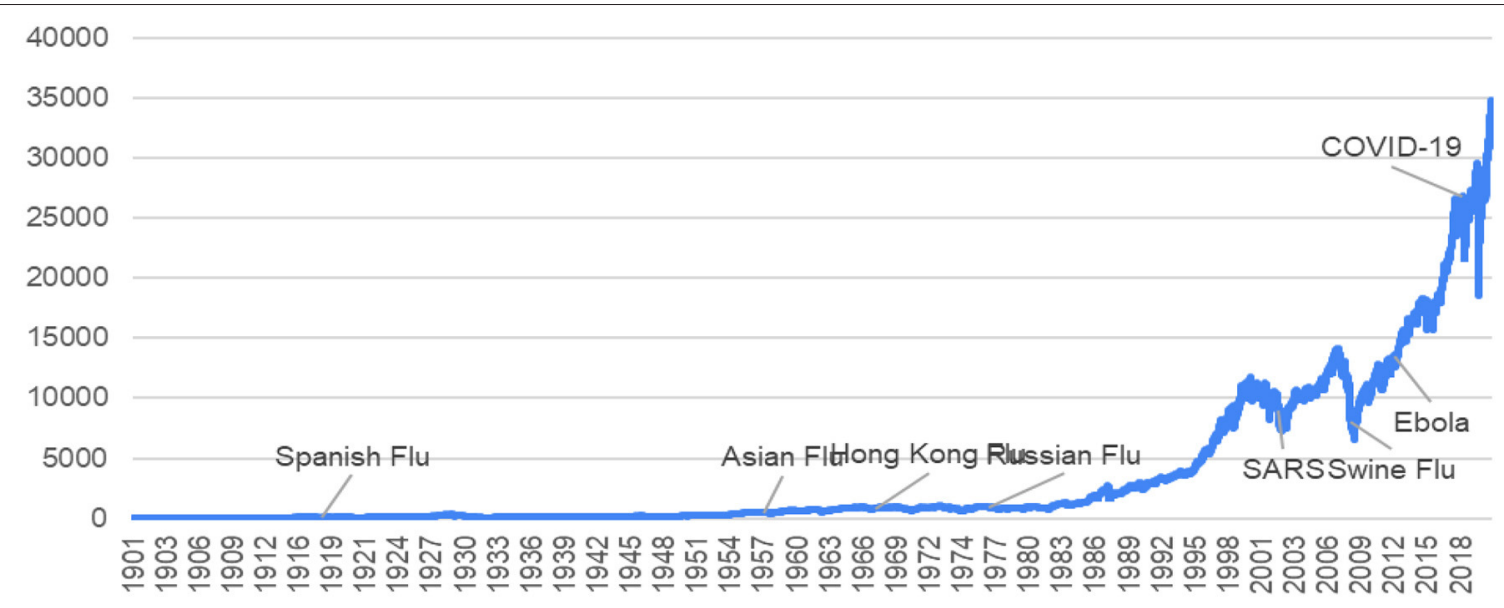

FIGURE 1 | World pandemics and the movement of the Dow Jones Industrial Average (DJIA).

treatments borne by public health care schemes. Third, our empirical results show that the stock market is informationally efficient about the COVID-19 pandemic.

The remainder of this study is organized as follows. Section Analysis of Historical Pandemic Records analyzes the statistical characteristics of the pandemic historical records. Section A Hedge for Public Health Care Schemes develops the hedge instruments for public health care schemes. Section Empirical Results shows the empirical results, and the final section offers conclusions.

\section{ANALYSIS OF HISTORICAL PANDEMIC RECORDS}

As shown in Table 2, the recorded frequency of pandemics ranges from one to five per 100 years, with an average of three. The number of deaths per pandemic changed substantially over time, Regarding the pandemic frequency over the past 300 years, roughly corresponding to the post-Industrial Revolution period, the outbreaks per 100 years increase twice as large as the average in earlier times (from 2 to 4 ). In addition to the abovementioned serious pandemics, Jones et al. (9) collected 335 emerging infectious diseases (EIDs) from 1940 to 2004 and shows such diseases have risen significantly over time. They found that the origins of EIDs are significantly corrected with socioeconomic, environmental, and ecological factors. Lindahl and Grace (10) also show EIDs are increasing, causing large losses in both human and animal lives, as well as huge costs to society locally and globally during the last few decades. Many factors contributing to EIDs include climate change, globalization, and urbanization, which are to some extent caused by humans after the post-Industrial Revolution period. Since the Wright brothers invented and flew the first airplane in 1903, people move more easily and quickly around the world than past due to advanced transportation, so will the virus accompanying humans. There were 4.2 billion air transport passengers in 2018-compared to 310 million in 1970. This mobility helped coronavirus' transfer
TABLE 2 | Pandemics frequency and average deaths.

\begin{tabular}{lcc}
\hline Period & Frequency & Average deaths (million) \\
\hline $1300-1400$ & 1 & 50 \\
$1400-1500$ & 1 & 0.017 \\
$1500-1600$ & 4 & 18.5 \\
$1600-1700$ & 1 & Unknown \\
$1700-1800$ & 5 & 0.65 \\
$1800-1900$ & 3 & 25.63 \\
$1900-2000$ & 5 & 20.53 \\
$2000-2021$ & 3 & 1.06
\end{tabular}

from China in 2020 to more than 60 countries in 2 months. The chance of epidemic becoming pandemic becomes large. It means the pandemic can cause a lot of infected individuals and deaths across several geographic areas in a short term.

The average recorded deaths per pandemic were more than 20 million from 1800 to 2000 (largely due to the 1918 pandemic that killed at least 50 million people). While the number of pandemic-related deaths may seem to be increasing, a pioneer in infectious disease research, Robert Koch, who employed an optical microscope to observe the infectious pathogen Bacillus anthracis in 1875 that allowed scientists to learn more about the virus than ever before, proposed "Koch's Law" as a guideline to describe the pathogenesis of infectious diseases. The Law guides scientist on how to isolate the microorganisms from diseased individuals and grown in the experimental host to find the cure method.

The average number of recorded deaths for the most recent three pandemics are less obvious than those that occurred before 2000, as innovations in medical technology allow us to quickly find effective treatments and vaccines for new diseases. The establishment of modern public health care systems also offers more medical treatment for citizens than in the past. As a result, the number of pandemic-related deaths are lower now than in the past, although their frequency is increasing. 


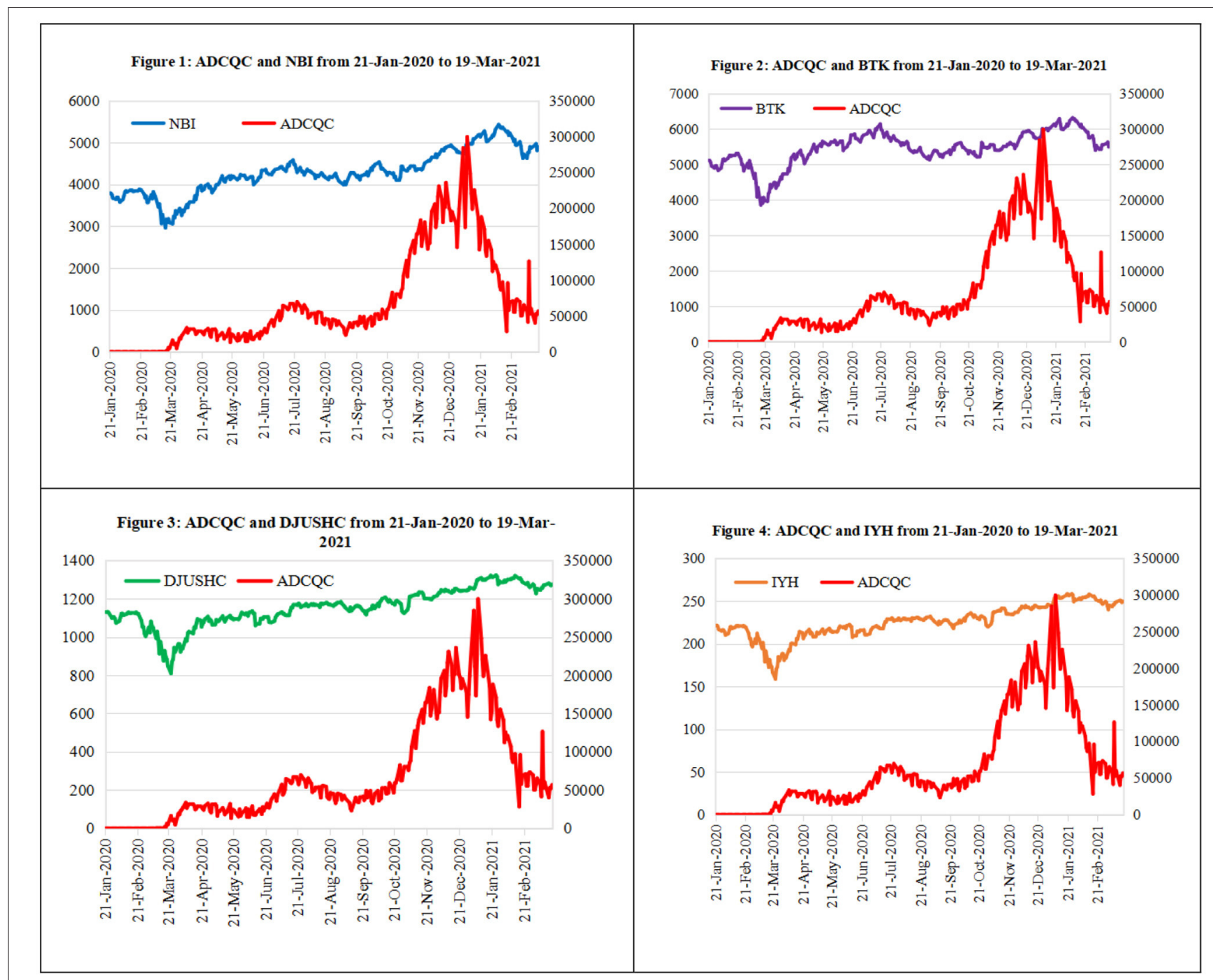

FIGURE 2 | The trendlines of ADCQC, NBI, BTK, DJUSHC, and IYH.

As a result of the industrial and agricultural revolutions, the standard of living in most countries has generally improved. At the same time, the world's population has increased, and the number of infected individuals naturally increases as the population grows. The United Nations estimated there were 7.9 billion people in the world at the end of 2020, and the number of confirmed cases of COVID-19 exceeded 138 million as of March 31, 2021. Although medical science has improved our ability to find treatments for pandemic diseases, the enormous cost of doing so creates another problem for the public health care system. A potential solution may be to employ new financial instruments to encourage private capital to help cover the large expenses caused by pandemics.

\section{A HEDGE FOR PUBLIC HEALTH CARE SCHEMES}

We define the gross inward premium $\mathrm{P}$ required to cover expected medical expenses $\mathrm{L}$, and additional expenses $\mathrm{s}$, as shown in Equation (1)

$$
P=E[L]+s
$$

Net revenue $X$ is simplified as premium income minus the total payoff for a claim $L$, expressed as

$$
X=P-L
$$

The volatility of profits $\sigma_{X}$ is equal to the volatility of losses $\sigma_{L}$.

\section{A Pandemic Bond as a Liability Hedge}

A public health scheme could issue $u$ units of pandemic bonds to share the liability of pandemic-related medical expenses. Such bonds are similar to catastrophe bonds but are linked to pandemic-induced disasters. A pandemic bond is designed to have a principal (face value) $M$ and an indemnity trigger point $K$, offering the contingent payment $H=\{L-$ 
TABLE 3 | Descriptive statistics.

\begin{tabular}{lccccc}
\hline Statistic & ADCQC & NBI & BTK & DJUSHC & IYH \\
\hline Mean & 65118.52 & 4278.053 & 5444.884 & 1152.883 & 225.613 \\
Maximum & 299562 & 5427.13 & 6319.77 & 1322.44 & 258.36 \\
Minimum & 0 & 2961.94 & 3855.67 & 809.48 & 158.63 \\
Std.Dev. & 64488.41 & 513.989 & 469.677 & 98.753 & 19.232 \\
Skewness & 1.314 & -0.025 & -0.956 & -0.62 & -0.632 \\
Kurtosis & 3.880 & 2.803 & 4.303 & 3.603 & 3.616 \\
Q (1\%) & 0 & 3062.5 & 3952.22 & 871.05 & 170.67 \\
Q (10\%) & 2.5 & 3634.455 & 4889.415 & 1047.225 & 205.32 \\
Q (25\%) & 23139 & 3986.13 & 5253.5 & 1098.61 & 214.98 \\
Q (50\%) & 43834.5 & 4258.785 & 5497.02 & 1159.42 & 227.17 \\
Q (75\%) & 80384 & 4579.42 & 5745.29 & 1230.72 & 240.71 \\
Q (90\%) & 178143.5 & 4996 & 6000.24 & 1283.835 & 250.92 \\
Q (99\%) & 248089 & 5361.57 & 6287.3 & 1319.53 & 257.96 \\
Jarque-Bera & 92.81 & 0.498 & 64.73 & 22.99 & 23.89 \\
Probability & 0.000 & 0.780 & 0.000 & 0.000 & 0.000 \\
Observations & 290 & & & & \\
\hline
\end{tabular}

ADCQC, The daily confirmed numbers of quarantined cases of the USA; NBI, NASDAQ Biotechnology Index; BTK, NYSE Arca Biotechnology Index; DJUSHC, Dow Jones U.S. Health Care Index; IYH, iShares U.S. Healthcare ETF.

TABLE 4 | Correlation matrix (The USA).

\begin{tabular}{lccccr}
\hline & ADCQC & NBI & BTK & DJUSHC & IYH \\
\hline ADCQC & 1.0000 & & & & \\
NBI & 0.6873 & 1.0000 & & & \\
BTK & 0.5378 & 0.9054 & 1.0000 & & \\
DJUSHC & 0.6832 & 0.9423 & 0.8446 & 1.0000 & \\
IYH & 0.6797 & 0.9418 & 0.8454 & 0.9998 & 1.0000 \\
\hline
\end{tabular}

TABLE 5 | Unit root test results.

\begin{tabular}{|c|c|c|c|c|c|c|}
\hline & \multicolumn{3}{|c|}{ Level } & \multicolumn{3}{|c|}{ First differences } \\
\hline & ADF & PP & KPSS & ADF & PP & KPSS \\
\hline ADCQC & -1.903 & -1.750 & $1.53^{\star \star \star}$ & $-17.891^{\star \star \star \star}$ & $-25.063^{\star \star \star}$ & 0.142 \\
\hline $\mathrm{NBI}$ & -0.997 & -1.141 & $2.02^{\star \star \star}$ & $-11.670^{\star \star \star \star}$ & $-20.542^{\star \star \star}$ & 0.0503 \\
\hline BTK & -1.600 & -1.871 & $1.2^{\star \star \star}$ & $-11.304^{\star \star \star}$ & $-20.132^{\star \star \star}$ & 0.0602 \\
\hline DJUSHC & -0.942 & -1.220 & $1.98^{\star \star \star}$ & $-11.162^{\star \star \star}$ & $-21.560^{\star \star \star}$ & 0.0907 \\
\hline $\mathrm{IYH}$ & -0.947 & -1.227 & $1.97^{\star \star \star}$ & $-11.093^{\star \star \star}$ & $-21.353^{\star \star \star}$ & 0.0897 \\
\hline
\end{tabular}

${ }^{* \star *},{ }^{* *}$, and ${ }^{*}$ indicate significance at the 1, 5, and 10\% levels, separately.

$K \mid(M+K) \geq L \geq K\}$, and charging a premium $p_{H}$. The scheme would then obtain the contingent compensation:

$$
L_{H}=u H
$$

The payment $\mathrm{p}_{H}$ made to bondholders would include the expected payoff $E[H]$ plus a risk premium $C_{H}$ :

$$
P_{H}=E[H]+C_{H}
$$

Net revenue with the hedge is expressed as follows:

$$
X_{H}=X-u P_{H}+u H
$$

The volatility of revenues will decrease because the pandemic bond covers some or all the medical expenses that exceed the threshold $K$, and the payments made to bondholders decrease the scheme's revenue if medical expenses are below $K$.

The volatility of revenues $\sigma_{X_{H}}$ for issuers of pandemic bonds is a function of $u$ :

$$
\sigma_{X_{H}}(u)=\sqrt{\sigma_{L}^{2}+u^{2} \sigma_{H}^{2}-2 u \rho_{H} \sigma_{L} \sigma_{H}}
$$

where $\rho_{H}$ denotes the correlation coefficient between $L$ and $H$.

\section{The Biotechnology Index for Asset Hedge}

A health care scheme may purchase $u$ units of a biotechnology index (or individual biotech stocks) $I$, with the goal of realizing capital gains from that position when a pandemic occurs. The initial value is denoted as $u I_{0}$. The value after the pandemic outbreak is $u I$.

The net revenue generated by the biotechnology index is as follows:

$$
X_{I}=X-u I_{0}+u I
$$

The volatility $\sigma_{X_{I}}$ of the position is a function of $u$ :

$$
\sigma_{X_{I}}(u)=\sqrt{\sigma_{L}^{2}+u^{2} \sigma_{I}^{2}-2 u \rho_{I} \sigma_{L} \sigma_{I}}
$$

where $\rho_{I}$ denotes the correlation coefficient between $L$ and $I$.

Suppose that the risk management objective is to reduce the profit volatility to achieve the variance ratio $\frac{\sigma_{X_{I}}}{\sigma_{X}}($ denoted by $d)$, where $0<d<1$. That is to say,

$$
\sigma_{X_{I}}(u)-(1-d) \sigma_{L}^{2} \leq 0
$$

In this case, the risk management objective above can be rewritten as

$$
u^{2}-2 \frac{\sigma_{L}}{\sigma_{X_{I}}} \rho u-\left(d^{2}-2 d\right)\left(\frac{\sigma_{L}}{\sigma_{X_{I}}}\right)^{2} \leq 0
$$

This quadratic inequality holds if and only if it has real solutions, where

$$
\begin{aligned}
& u_{1}=\frac{\sigma_{L}}{\sigma_{X_{I}}}\left(\rho-\sqrt{\rho^{2}-2 d+d^{2}}\right) \text { and } \\
& u_{2}=\frac{\sigma_{L}}{\sigma_{X_{H}}}\left(\rho+\sqrt{\rho^{2}-2 d+d^{2}}\right)
\end{aligned}
$$

In this case, the following inequalities must hold to ensure the existence of real roots

$$
\rho>\sqrt{2 d-d^{2}} \text { or } \rho<-\sqrt{2 d-d^{2}}
$$

Note that the absolute value of the correlation coefficient must exceed the threshold value of $\sqrt{2 d-d^{2}}$ to achieve the risk 
TABLE 6 | Engle-Granger cointegration tests results.

\begin{tabular}{lcccc}
\hline & NBI & BTK & DJUSHC & IYH \\
\hline ADCQC & $-3.273^{\star}$ & -2.977 & $-3.486^{\star \star}$ & $-3.464^{\star *}$ \\
Observations (1st step) & 290 & 290 & 290 & 290 \\
Observations (test) & 289 & 289 & 289 & 289 \\
\hline
\end{tabular}

${ }^{\star \star \star},{ }^{\star *}$, and ${ }^{*}$ indicate significance at the 1, 5, and $10 \%$ levels, separately.

TABLE 7 | OLS regression analysis results.

\begin{tabular}{lccc}
\hline & $\mathbf{( 1 )}$ & $\mathbf{( 2 )}$ & $\mathbf{( 3 )}$ \\
\cline { 2 - 4 } & $\mathbf{N B I}$ & DJUSHC & IYH \\
\hline Intercept & $3921.349^{\star \star \star}$ & $1084.757^{\star \star \star}$ & $212.4136^{\star \star \star}$ \\
ADCQC & $(31.23898)$ & $(6.033766)$ & $(1.18033)$ \\
& $0.0054778^{\star \star \star}$ & $0.0010462^{\star \star \star}$ & $0.0002027^{\star \star \star}$ \\
Observations & $(0.0003412)$ & $(0.0000659)$ & $(0.0000129)$ \\
R-squared & 290 & 290 & 290 \\
Adj R-squared & 0.4723 & 0.4667 & 0.4620 \\
\hline
\end{tabular}

${ }^{* * *},{ }^{* *}$, and ${ }^{*}$ indicate significance at the 1,5 , and $10 \%$ levels, separately. ADCQC is the independent variable. The dependent variables include NBI, DJUSHC, and IYH.

management objective. This threshold increases with the ratio $d$, which means that a high correlation will reduce revenue volatility. If the correlation coefficient is positive, the scheme creates a long position of $u_{1}$ units, because $u_{1}<u_{2}$ lowers hedging costs. Conversely, if the correlation coefficient is negative, the scheme creates a short position of $-u_{2}$ units given that $-u_{2}<-u_{1}$.

\section{EMPIRICAL RESULTS}

This section illustrates the relationship between the spread of COVID-19 and stocks related to medicine and biotechnology. As the pandemic's severity increased, the daily number of confirmed cases in the U.S. (denoted by ADCQC) increased. The stocks associated with epidemic prevention include medical treatments and vaccine development. For this study, we chose the following four indices, some represented by index-tracking ETFs that trade on U.S. stock exchanges, to characterize these types of assets: the NASDAQ Biotechnology Index (denoted by NBI), the NYSE Arca Biotechnology Index (denoted by BTK), the Dow Jones U.S. Health Care Index (denoted by DJUSHC), and the iShares U.S. Healthcare ETF (denoted by IYH). The data were obtained from January 2, 2020 to March 31, 2021, a total of 290 observations per item, from the Wind database in China.

Figure 2 shows that the levels of the four indices trended in the same direction as the ADCQC, indicating that the biotechnology and healthcare indices reflected the severity of the COVID-19 pandemic. Based on this, we continued with the analysis. Table 3 shows that changes in the NBI are approximately normally distributed, as its skewness and kurtosis are close to 0 and 3 , respectively, and the Jarque-Bera test does not reject the
TABLE 8 | OLS regression analysis results.

\begin{tabular}{lccc}
\hline & $\mathbf{( 1 )}$ & $\mathbf{( 2 )}$ & $\mathbf{( 3 )}$ \\
\cline { 2 - 4 } & $\mathbf{N B I}$ & DJUSHC & IYH \\
\hline Intercept & $-303778.5^{\star \star \star}$ & $-449227.3^{\star \star \star}$ & $-449067.3^{\star \star \star}$ \\
ADCQC & $(23139.43)$ & $(32513.75)$ & $(32817.34)$ \\
& $86.23012^{\star \star \star}$ & $446.1388^{\star \star \star}$ & $2279.064^{\star \star \star}$ \\
Observations & $(5.37038)$ & $(28.09958)$ & $(144.9349)$ \\
R-squared & 290 & 290 & 290 \\
Adj R-squared & 0.4723 & 0.4667 & 0.4620 \\
\hline
\end{tabular}

${ }^{\star * *}$, **, and ${ }^{*}$ indicate significance at the 1, 5, and $10 \%$ levels, separately. The independent variables are $\mathrm{NBI}, \mathrm{DJUSHC}$, and IYH. ADCQC is a dependent variable.

null hypothesis. BTK, DJUSHC, and IYH are clearly negatively skewed and are leptokurtic, and their Jarque-Bera tests reject the hypothesis of a normal distribution. The correlation coefficients between ADCQC and the indices are $>0.6$, except for BTK (as shown in Table 4). Therefore, according to Equation (12), derivatives based on these underlying indices or ETFs could be used to hedge pandemic expenses.

The results of augmented Dickey-Fuller, Phillips-Perron, and Kwiatkowski-Phillips-Schmidt-ShinK tests shown in Table 5 show that their first differences reject the presence of a unit root. Furthermore, results of the Engle-Granger test shown in Table 6 indicate the existence of cointegration between ADCQC, NBI, DJUSHC, and IYH, but not BTK. Therefore, in our regressions, we assume that $X=\mathrm{ADCQC}$ and $Y=(\mathrm{NBI}, \mathrm{DJUSHC}, \mathrm{IYH})$. First, we regress $Y$ on $X$ as follows:

$$
Y=b+X
$$

where $b$ is an intercept term. The empirical results in Table 7 show that the coefficients of ADCQC are significantly positive, indicating that ADCQC leads to changes in NBI, DJUSHC, and IYH.

Second, we regress $\mathrm{X}$ on $\mathrm{Y}$ to determine whether NBI, DJUSHC, and IYH can reflect the pandemic severity in advance.

$$
X=c+Y
$$

where $c$ is an intercept term. The results provided in Table 8 show that the coefficients for NBI, DJUSHC, and IVH are significantly positive, indicating that the U.S. stock market exhibits informational efficiency about the COVID-19 pandemic.

\section{CONCLUSIONS}

Trends from globalization, urbanization, and climate change are fueling the increased incidence of pandemic outbreaks (9, 10). The pandemics causing large losses in both human and animal lives have challenged public health care schemes in many countries. This study analyzes statistical characteristics of pandemics using historical records since the Middle Ages (11) and found that over the past 300 years, roughly corresponding to 
the post-Industrial Revolution period, the pandemic outbreaks per one 100 years increase twice as large as the average in earlier times (from 2 to 4 ). The average number of recorded deaths per pandemic was more than 20 million from 1800 to 2000 . The average recorded deaths in the recent three pandemics are less obvious than those since 2000. So, the pandemic deaths are not greater than those in previous periods, although the frequency has increased. The contributions come from both innovations in medical technology and the establishment of a modern public health care system.

Compared to literature focusing on the effect of the COVID19 pandemic on the financial market (1-4), this paper aims to find financial instruments for the public health care schemes (PHCS) to hedge pandemic risks. During the pandemic period, the PHCS bear a large number of medical expenses. A biotechnology investment portfolio assets can help the PHCS to increase their assets. Pandemic bonds can contribute to reducing liabilities. Empirical results indicate that such financial instruments may be practical, as the NASDAQ Biotechnology

\section{REFERENCES}

1. Burdekin RCK. Death and the stock market: international evidence from the Spanish flu. Appl Econ Lett. (2020) 1-9. doi: 10.1080/13504851.2020.18 28802

2. Bai L, Wei Y, Wei G, Li X, Zhang S. Infectious disease pandemic and permanent volatility of international stock markets: a long-term perspective. Fin Res Lett. (2021) 40:101709. doi: 10.1016/j.frl.2020. 101709

3. Chang CP, Feng GF, Zheng M. Government fighting pandemic, stock market return, and COVID-19 virus outbreak. Emerg Mark Fin Trade. (2021) 57:1-18. doi: 10.1080/1540496X.2021.1873129

4. Zhang D, Hu M, Ji Q. Financial markets under the global pandemic of COVID-19. Fin Res Lett. (2020) 36:101528. doi: 10.1016/j.frl.2020. 101528

5. Wang JY, Wu WL, Wu YC, Yang MJ. How to manage long-term financial self-sufficiency of a natural catastrophe insurance fund? The feasibility of three bailout programmes. Eur Fin Manage. (2017) 23:951-74. doi: 10.1111/eufm.12111

6. Wu YC. Reexamining the feasibility of diversification and transfer instruments on smoothing catastrophe risk. Insurance Math Econ. (2015) 64:54-66. doi: $10.1016 /$ j.insmatheco

7. Wu YC, Yang MJ. The effectiveness of asset, liability, and equity hedging against the catastrophe risk: the cases of winter storms in north America and Europe. Eur Fin Manage. (2018) 24:893-918. doi: 10.1111/eufm.12143

8. Gründl H, Regele F. Pandemic Insurance Through Pandemic Partnership Bonds. A Fully Funded Insurance Solution in a Public Private Partnership (No. 86). SAFE Policy Letter (2020). Available online at: http://nbn-resolving.de/ urn:nbn:de:hebis:30:3-534499
Index, Dow Jones U.S. Health Care Index, and iShares U.S. Healthcare ETF have positively correlated with the daily numbers of COVID-19 confirmed cases in the U.S. In addition, we found that the U.S. stock market shows informational efficiency with respect to the COVID-19 pandemic.

\section{DATA AVAILABILITY STATEMENT}

The raw data supporting the conclusions of this article will be made available by the authors, without undue reservation.

\section{AUTHOR CONTRIBUTIONS}

ZL: supervision, conceptualization, and resources. Y-CW: conceptualization, methodology, and writing-original draft, reviewing and editing. M-CW: methodology and writing-original draft preparation. YD: data curation and formal analysis. T-TN: software, visualization and editing. All authors contributed to the article and approved the submitted version.

9. Jones KE, Patel NG, Levy MA, Storeygard A., Balk D, Gittleman JL, et al. Global trends in emerging infectious diseases. Nature. (2008) 451:990-3. doi: $10.1038 /$ nature 06536

10. Lindahl JF, Grace D. The consequences of human actions on risks for infectious diseases: a review. Infect Ecol Epidemiol. (2015) 5:30048. doi: 10.3402/iee.v5.30048

11. Pompella M, Scordis NA. The Palgrave handbook of unconventional risk transfer. In: Pompella M, Scordis NA, editors. The Palgrave Handbook of Unconventional Risk Transfer. New York, NY: Springer International Publishing (2017). p. 467-71. doi: 10.1007/978-3-319-59297-8

Conflict of Interest: The authors declare that the research was conducted in the absence of any commercial or financial relationships that could be construed as a potential conflict of interest.

Publisher's Note: All claims expressed in this article are solely those of the authors and do not necessarily represent those of their affiliated organizations, or those of the publisher, the editors and the reviewers. Any product that may be evaluated in this article, or claim that may be made by its manufacturer, is not guaranteed or endorsed by the publisher.

Copyright (c) $2021 \mathrm{Liu}, \mathrm{Wu}$, Wang, Ding and Nguyen. This is an open-access article distributed under the terms of the Creative Commons Attribution License (CC BY). The use, distribution or reproduction in other forums is permitted, provided the original author(s) and the copyright owner(s) are credited and that the original publication in this journal is cited, in accordance with accepted academic practice. No use, distribution or reproduction is permitted which does not comply with these terms. 